\title{
(6) OPEN ACCESS \\ Improving patient waiting times: a simulation study of an obesity care service
}

\author{
Antuela A Tako, ${ }^{1}$ Kathy Kotiadis, ${ }^{2}$ Christos Vasilakis, ${ }^{3}$ Alexander Miras, ${ }^{4}$ \\ Carel W le Roux ${ }^{4,5}$
}

\begin{abstract}
${ }^{1}$ School of Business and Economics, Loughborough University, Loughborough, UK ${ }^{2}$ Warwick Business School, University of Warwick, Coventry, UK

${ }^{3} \mathrm{UCL}$ Clinical Operational Research Unit, University College London, London, UK

${ }^{4}$ Imperial Weight Centre, Imperial College London, London, UK

${ }^{5}$ Experimental Pathology, UCD Conway Institute, School of Medicine and Medical Science, University College Dublin, Dublin, Ireland
\end{abstract}

\section{Correspondence to} Dr Antuela A Tako, School of Business and Economics, Loughborough University, Richard Morris Building, Ashby Road, Loughborough LE11 3TU, UK; a.takou@lboro.ac.uk

Received 28 April 2013 Revised 5 August 2013 Accepted 27 August 2013 Published Online First 19 September 2013

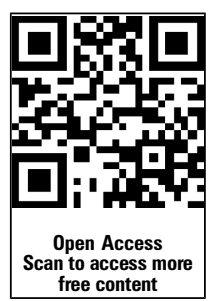

\section{Linked}

http://dx.doi.org/10.1136/ bmjqs-2013-002742

To cite: Tako AA, Kotiadis $\mathrm{K}$, Vasilakis C, et al. BMJ Qual Saf 2014;23:373-381.

\begin{abstract}
Background Obesity care services are often faced with the need to adapt their resources to rising levels of demand. The main focus of this study was to help prioritise planned investments in new capacity allowing the service to improve patient experience and meet future anticipated demand.

Methods We developed computer models of patient flows in an obesity service in an Academic Health Science Centre that provides lifestyle, pharmacotherapy and surgery treatment options for the UK's National Health Service. Using these models we experiment with different scenarios to investigate the likely impact of alternative resource configurations on patient waiting times.
\end{abstract}

Results Simulation results show that the timing and combination of adding extra resources (eg, surgeons and physicians) to the service are important. For example, increasing the capacity of the pharmacotherapy clinics equivalent to adding one physician reduced the relevant waiting list size and waiting times, but it then led to increased waiting times for surgical patients. Better service levels were achieved when the service operates with the resource capacity of two physicians and three surgeons. The results obtained from this study had an impact on the planning and organisation of the obesity service. Conclusions Resource configuration combined with demand management (reduction in referral rates) along the care service can help improve patient waiting time targets for obesity services, such as the 18 week target of UK's National Health Service. The use of simulation models can help stakeholders understand the interconnectedness of the multiple microsystems (eg, clinics) comprising a complex clinical service for the same patient population, therefore, making stakeholders aware of the likely impact of resourcing decisions on the different microsystems.

\section{INTRODUCTION}

Obesity is a major concern in a number of countries worldwide. ${ }^{1}$ Thirty per cent and $24 \%$ of adults in the USA and UK, respectively are currently classified as obese, and these figures are expected to double in the future. ${ }^{2}{ }^{3}$ The clinical treatment of obesity has become part of obesity care services delivered by dedicated care providers. ${ }^{4}$

So far, mathematical and computer modelling efforts with regards to obesity have concentrated on developing epidemiological models that estimate expected obesity trends and healthcare expenditure due to related diseases in the USA and the UK. ${ }^{4}{ }^{5}$ Given that multidisciplinary obesity centres are a relatively new service, at least to the National Health Service (NHS) in England, studies looking at their performance from an operational perspective have not been reported in the literature. An obesity care service typically forms a complex interconnected clinical service comprising multiple microsystems that provide a range of non-surgical and surgical services to the same patient population. ${ }^{6}$

Obesity care service performance is typically judged using targets aimed at ensuring patients' right to accessing services within a maximum waiting time. In the UK, the 18-week target from when a patient is referred to when treatment is provided ${ }^{7} 8$ has received significant attention in the last 10-15 years, and has been used to evaluate the performance of NHS institutions. This target is also used to evaluate the performance of obesity centres, however, for the purposes of obesity treatment, this target needs to be measured differently to accommodate for the time the patient needs to prepare to receive some specific treatments 
such as obesity surgery. Further detail about how these targets are measured is provided in the Methods section.

This paper reports on a simulation study undertaken to help prioritise planned investments in new capacity that will allow the service to improve patient experience and meet future anticipated demand. We chose to use discrete event simulation (DES) as it is generally considered appropriate for modelling and evaluating the allocation of resources in the health context. ${ }^{9}{ }^{10}$ Its overall aim is to evaluate the likely effect that the capacity of different resource configurations has on patient waiting times in a UK-based obesity service situated in an Academic Health Science Centre. The novelty of the study is that multiple microsystems have been included in the model rather than the single microsystem (eg, an outpatient clinic) usually modelled in simulation studies. ${ }^{11-16}$ This in turn has enabled us to explore targets such as the ' 18 weeks' target that involve a longer part of the patient journey through a number of clinics within the obesity system. A number of computer models were used to explore the impact of alternative configurations of resources on the emerging waiting lists. These models explored the following options:

- Increasing capacity to meet demand, that is, employing additional clinical staff (surgeons and physicians).

- Managing demand through a reduction in patient referral rates into the service.

Although the results obtained are specific to the particular service, the methods and findings could be useful to other similar centres within and outside the UK.

\section{METHODS}

\section{The care setting}

The obesity care service studied was designated as an International Centre of Excellence for bariatric surgery by the Surgical Review Corporation and one of the preferred providers of bariatric surgery services for London and Northern Ireland. The service providers wanted to understand how the 18 week target could be consistently met in the foreseeable future, without adding unnecessary capacity, by employing new resources such as surgeons and physicians. The service was experiencing, at the time of the study (2009), increasing numbers of referrals and an increased pressure to meet the demand for consultation and treatment. The pressure was mostly experienced in the parts of the system treating patients with pharmacotherapy (medication) and surgery. The service referrals were increasing each year at an exponential rate which made planning difficult. In addition stakeholders found it difficult to consider the effect of adding resources on the entire system. A visual interactive simulation tool was considered appropriate in bridging the stakeholders' views.

The treatment of obesity focuses on the reduction of body weight using three different options depending on patient choice: a change in lifestyle, pharmacotherapy and bariatric surgery (also known as obesity surgery). The first option involves diet, exercise and behavioural change. The second option involves the administration and management of weight loss medications over a long period. The third and final option is surgery. ${ }^{17}$ In the NHS the three most common types of surgical interventions are gastric band, sleeve gastrectomy and gastric bypass. ${ }^{18}$ The choice of treatment is made based on patient preferences and health indicators such as the body mass index and specific comorbidities.

Patients were referred to the obesity care service either from primary care services (general practitioners) or from other secondary care services (as a result of serious comorbidities related to obesity). A group induction session was organised once a week for newly referred patients, where members of the team (physician, surgeon and nurses) explained treatment options. Patients completed a questionnaire with details of their health conditions and treatment preferences. Next, a specialist nurse screened the questionnaires and referred patients to one of the three medical outpatient clinics which focused on preparing patients for the lifestyle, pharmacotherapy or surgery treatment options.

The lifestyle clinic led by dieticians operated twice a week. Patients attended in total six consultation visits, on average 1 month apart. After that patients were discharged and advised to continue the dietary regime for life, while also having the option of attending specific lifestyle group support sessions.

The pharmacotherapy clinic led by a physician operated weekly. Two types of medication therapies were typically prescribed, reviewed initially after a 3 months period and 9 months thereafter. Patients successfully treated were discharged to the care of the general practitioner to continue on a lifelong treatment. If one type of drug did not work for the patient, the second type of drug was prescribed. If none of the drug types worked, patients were either referred to the lifestyle or surgical clinic or discharged.

The surgical care component of the obesity service involves a range of outpatient appointments and a surgical procedure. Patients were first seen in an outpatient clinic, called the 'Eligibility clinic', led by a physician and psychiatrist, who reviewed the patient's history and assessed whether surgery would be appropriate. Patients, with psychological comorbidities that need further optimisation were sent for a 3-month psychiatric review and if a satisfactory improvement was achieved, they were then referred on for a surgical opinion. In the next clinic called the 'Decision clinic', a surgeon and dietician assessed the patient to establish if he/she can safely have an operation. Following the decision to operate, patients were registered on the surgery waiting list. Before their scheduled operation, they were reviewed and educated in a 'Pre-assessment clinic' led by an anaesthetist and a specialist nurse. If the patient passed the necessary 
health checks he/she was scheduled for one of the three types of surgical interventions (gastric band, sleeve gastrectomy or gastric bypass). The number of operations scheduled on an operating list would vary depending on the type of surgery. Patients were admitted on the day of surgery. After operation postoperative care was provided depending on the type of surgery. Patients were then discharged from hospital and seen as follow-up cases at the medical or surgical outpatient clinics under a shared care arrangement.

\section{The simulation model}

The obesity care pathway described above was represented in a simulation model built using Simul8, a DES software. ${ }^{19}$ The main objective was to identify the impact of capacity changes in resources (namely surgeons and physicians) and patient referral rates on patient waiting times. Capacity is modelled as the available patient appointments (slots). Stakeholders determine this in practice by translating the available resources (eg, physicians, surgeons, nurses, dieticians, beds, rooms, etc) of each microsystem into available patient capacity. The model runs for one simulated year with a time unit of 1 day. Patient movement is best represented in days for two main reasons. First the overall system in simulation terms is slow moving as it takes several weeks for a typical patient to move through the system. Second, the individual microsystems (eg, clinics) are modelled as patient slots (capacity) which do not require a time unit lower than a day as it would be unlikely to attend two clinics within a day. Results on patient waiting times are represented in multiples of days, which are automatically converted into weeks to fit with the targets of interest (eg, 18 week target). Patients are shown to arrive into the model in appropriate intervals and can follow various routes within the obesity system. These routes are determined by probability distributions. Movement of patients to the next process (eg, clinic) is determined by the available capacity. If there is no available capacity, patients are held in the model in queues, which conceptually fit waiting lists. Patients are assigned a range of attributes such as time stamps at different points within the model in order for the calculations of waiting times to be performed.

We chose DES because it can depict the concept of individual patients 'competing' for different types of resources (eg, a slot in the operating theatre list or a postoperative bed) and thus making it possible to model the impact of different levels of available resources and referrals on waiting times. Furthermore, the software can graphically display on screen the movement of patients, which members of the obesity team found useful to gain an overall understanding of the obesity care pathway. Figure 1 shows a flowchart of the flow of patients within the obesity care pathway and the simulation model. Table 1 provides a summary of the objects, model parameters and distributions used in the model, which further explain the simulation model developed.

As it is the case in modelling studies, some aspects of the real life service which were not relevant to the objectives of the study were not modelled and others were modified for simplification purposes. The assumptions and simplifications made are listed below:

- The capacity relevant to the study was mostly related to the number of physicians and surgeons. This was due to the difficulties when it comes to increasing these resources because of costs and limited availability in expertise. Other staff specialties (ie, nurses, dietician, etc.) are indirectly modelled as capacity in some parts of the system (eg, lifestyle clinics) but in this system their availability exceeded demand. Infrastructure components (eg, equipment and operating theatres) were a secondary concern when determining the capacity.

- Repeat outpatient appointments for patients returning for regular check-ups after treatment were not included. In fact, follow-up clinics were being established in primary care which followed the agenda of the NHS plan, but also allowed an almost unlimited capacity in principle as GPs would take up the follow-up care for uncomplicated patients.

- While placement of patients on the surgery waiting list is in reality more complex, taking into consideration patient preferences and fulfilment of requirements for surgery, in the model they are allocated an operation using a simplified first in first out rule.

It is standard practice in DES to improve the accuracy of the results by removing the initial transient effects (due to the simulated service starting empty) and by running the simulation several times to account for the variability in the input parameters. ${ }^{20} 21$ Statistical estimations informed our choice of using a warm-up period of 1 year and execute 30 simulation runs for each model configuration. ${ }^{22}$ The computer model then continues to run for a further year whereby the results show the level of the different performance measures calculated at that point in time.

A number of models were developed, including the baseline model, representing the obesity service running a year into the future as it was resourced at the time of the study, with the equivalent capacity resulting from operating with one surgeon and one physician. The remaining models represented other future scenarios of different options, which were previously agreed with the obesity care team. These models forecast the future performance of the service under variations of the following parameters:

- Number of surgeons: additional surgeons are represented as multiples of the capacity of services requiring a surgeon in Decision clinic and Operation theatre slots

- Number of physicians: additional physicians are represented as multiples of the capacity of services requiring a 


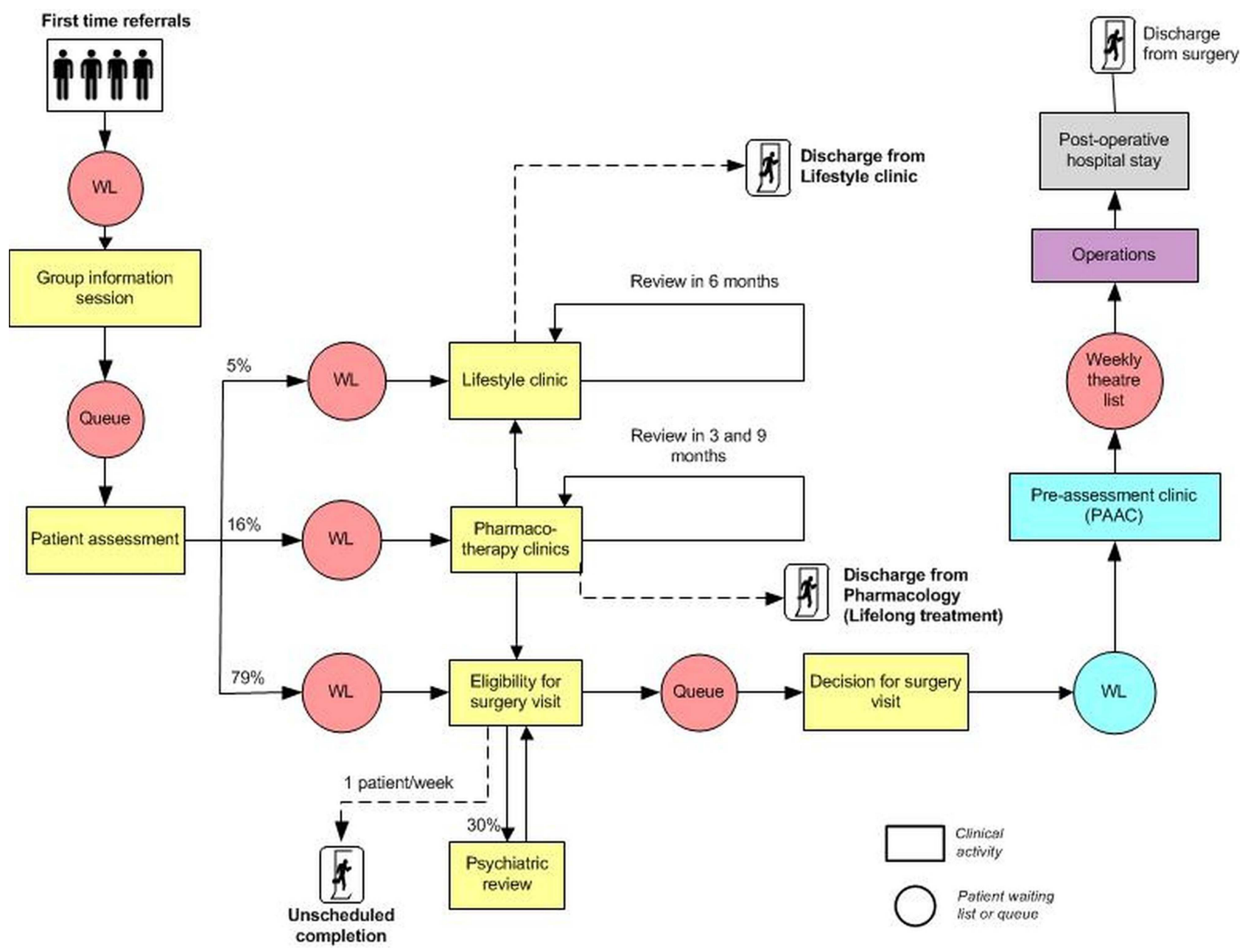

Figure 1 Flow chart showing the process flow within the obesity service. WL, waiting list.

physician in Group Induction, Pharmacotherapy clinic and Eligibility clinic

- Managing demand (referrals): reducing patient referrals to half of the baseline figures

Six scenarios (models) representing the feasible solution space were selected by the stakeholders. These scenarios look 1 year into the future (table 2 ).

\section{Data collection}

In order to populate the model's input parameters we obtained real life data from members of the obesity care service. The data used are detailed in table 1 , where the data sources are also explained. The obesity service was regularly audited which meant that some data such as number of patients in the different waiting lists, number of patients discharged, etc, was available in reasonable quantity. These are detailed in table 1 as existing data. In most cases, data referring to the proportion of patients that choose a specific treatment were collected based on a randomly chosen sample of 60 patients from a database containing 600 patients (every 1 patient in 10 was chosen from the existing patient database). Some of the data, such as the waiting time between clinics, were not known with accuracy and it was not possible to estimate empirically, hence informed guesses were made and approximate distributions were used in the model such as the triangular distribution (see table 1). Data on patient referrals were also estimated based on existing numbers accounting for the increased future demand for obesity services, hence slightly higher than the existing numbers. The source is detailed as expert opinion.

\section{Performance indicators}

We were mainly interested in patient waiting list size and times as these indicators are used by senior management to assess the performance of the obesity care service.

- Waiting list size for Group Induction: the number of first time patients on the waiting list for group induction session.

- Waiting list size for Pharmacotherapy clinic: the number of patients waiting to be seen in the Pharmacotherapy clinic.

- Waiting list size for Operations: the total number of surgical patients (who opted for surgical intervention at group induction), waiting for surgery at any point in the surgical pathway. This includes the waiting list for the 
Table 1 Input parameters to simulation model in baseline scenario

\begin{tabular}{|c|c|c|c|c|}
\hline Parameter & Resources & $\begin{array}{l}\text { Value in baseline } \\
\text { scenario }\end{array}$ & $\begin{array}{l}\text { Distribution } \\
\text { type }\end{array}$ & $\begin{array}{l}\text { Data } \\
\text { sources }\end{array}$ \\
\hline Referral rate & & 100 patients/month & Poisson & Expert opinion \\
\hline Group induction (one group session per week) & $\begin{array}{l}\text { Nurse } \\
\text { Physician Surgeon }\end{array}$ & Up to 20 patients/week & & Existing data \\
\hline \multicolumn{5}{|l|}{ Following group induction } \\
\hline Patient assessment & & $93 \%$ & Bernoulli & Existing \\
\hline Do not continue & & $7 \%$ & Bernoulli & Data \\
\hline Patient assessment (once a week) & Nurse & Up to 20 patients/week & & \\
\hline \multicolumn{5}{|l|}{ Following patient assessment } \\
\hline Lifestyle clinic & & $5 \%$ & Bernoulli & Existing \\
\hline Pharmacotherapy clinic & & $16 \%$ & Bernoulli & Data \\
\hline Eligibility for surgery clinic & & $79 \%$ & Bernoulli & \\
\hline Lifestyle clinic (two group sessions per week) & Dietician & Up to 8 patients/week & & Existing data \\
\hline \multicolumn{5}{|l|}{ Six separate appointments/patient } \\
\hline Time period between appointments & & 20 working days (1 month) & Triangular & Expert opinion \\
\hline Pharmacotherapy clinic (once a week) & Physician & Up to 14 patients/ week & & Existing data \\
\hline Following Pharmacotherapy & & & & Expert \\
\hline Receive drugs (drug A) & & $84 \%$ success rate & Bernoulli & opinion \\
\hline Receive drug $B$ (if drug $A$ fails) & & $80 \%$ success rate & Bernoulli & \\
\hline Time period for second appointment & & 90 days (3 months) & Triangular & \\
\hline Time period for third appointment & & 120 days (6 months) & Triangular & \\
\hline If drugs $A$ and $B$ fail, & & & & Expert \\
\hline Referral to surgery & & $15 \%$ & Bernoulli & Opinion \\
\hline Referral to lifestyle clinic & & $10 \%$ & Bernoulli & \\
\hline Discharged & & $75 \%$ & Bernoulli & \\
\hline Eligibility clinic (outpatients) & $\begin{array}{l}\text { Physician } \\
\text { Psychiatrist }\end{array}$ & Up to 10 patients/week & & Existing data \\
\hline Following Eligibility clinic & & & & Existing \\
\hline Decision clinic (surgery) & & $60 \%$ & & Data \\
\hline Psychiatric review & & $30 \%$ & & \\
\hline DNA surgery & & $10 \%$ & & \\
\hline Decision (for surgery) clinic & Surgeon Dietician & 8 patients/week & & Existing data \\
\hline $\begin{array}{l}\text { Preassessment clinic ( } 2 \text { weeks before the scheduled } \\
\text { operation) }\end{array}$ & Anaesthetist Nurse & 8 patients/week & & Existing data \\
\hline Operations (three types of surgical procedures) & $\begin{array}{l}\text { Surgeon } \\
\text { Anaesthetist }\end{array}$ & $\begin{array}{l}3 \text { half day theatre } \\
\text { lists/week }\end{array}$ & & Existing data \\
\hline Gastric band ( $1 \mathrm{~h}$ procedure) & & $19 \%$ & Bernoulli & \\
\hline Sleeve gastrectomy $(1.5 \mathrm{~h})$ & & $22 \%$ & Bernoulli & \\
\hline Gastric bypass (2 h) & & $59 \%$ & Bernoulli & \\
\hline Postoperative length of stay following & Beds & $\begin{array}{l}\text { Depending on type of } \\
\text { surgery }\end{array}$ & & Expert opinion \\
\hline Gastric band & & 1 day & & \\
\hline Sleeve gastrectomy & & 2 days & & \\
\hline Gastric bypass & & 2 days & & \\
\hline
\end{tabular}

Eligibility clinic, Decision clinic, surgery (patients who are allocated a date) and the weekly operating list (ie, patients scheduled for operation).

- Waiting time to operation: the total time (in weeks) patients spent in the system from first referral to the day of operation.

- 18 week targets: the proportion of patients waiting more than 18 weeks from referral to receiving treatment. Two separate 18 -week targets were calculated, specific to the obesity pathway as opposed to an overall 18 week target used in other clinical areas, ${ }^{7}$ where patients require shorter timescales to first treatment. The first target counts the combined waiting time from first time referral until a first treatment is provided (in Eligibility or Pharmacotherapy clinic). The second target is counted only for surgical patients, where the clock starts counting from Eligibility clinic until surgery. Effectively the clock stopped when the patient was seen for the first time and 
Table 2 Parameters defining the six simple future scenarios (all values represent patient slots per week unless otherwise stated)

\begin{tabular}{|c|c|c|c|c|c|c|c|}
\hline Scenario & Resources & $\begin{array}{l}\text { Monthly patient } \\
\text { referrals (average) }\end{array}$ & $\begin{array}{l}\text { Group } \\
\text { induction }\end{array}$ & $\begin{array}{l}\text { Pharma-cotherapy } \\
\text { clinic }\end{array}$ & $\begin{array}{l}\text { Eligibility clinic } \\
\text { (surgery) }\end{array}$ & $\begin{array}{l}\text { Decision clinic } \\
\text { (surgery) }\end{array}$ & Operations \\
\hline Baseline & $\begin{array}{l}1 \text { surgeon, } \\
1 \text { physician }\end{array}$ & 100 & 20 & 14 & 10 & 8 & 6 \\
\hline 1 & $\begin{array}{l}2 \text { surgeons, } \\
1 \text { physician }\end{array}$ & 100 & 20 & 14 & 10 & 16 & 12 \\
\hline 2 & $\begin{array}{l}2 \text { surgeons } \\
2 \text { physicians }\end{array}$ & 100 & 40 & 28 & 10 & 16 & 12 \\
\hline 3 & $\begin{array}{l}3 \text { surgeons, } \\
2 \text { physicians }\end{array}$ & 100 & 40 & 28 & 20 & 24 & 18 \\
\hline 4 & $\begin{array}{l}2 \text { surgeons, } \\
2 \text { physicians }\end{array}$ & 55 & 40 & 28 & 20 & 16 & 12 \\
\hline 5 & $\begin{array}{l}3 \text { surgeons, } \\
2 \text { physicians }\end{array}$ & 55 & 40 & 28 & 30 & 24 & 18 \\
\hline
\end{tabular}

then it restarted at zero when the decision/referral to proceed to surgery was made. At the time of the study these divisions were of interest to the members of the obesity centre. However, other centres may view the interpretation of the 18 week target differently. A different calculation would require a change in the model coding for such calculations but would not invalidate the model itself. The lifestyle clinic was not included in our findings as it was underused and the computer model and centre data supported that finding.

For each performance indicator, we used the output from the 30 runs per scenario to calculate the point estimates (mean) and 95\% CI values.

\section{Model validation}

The aim of validation in simulation modelling is to enable the modelling team and stakeholders to gain sufficient confidence in the model. ${ }^{21}$ The simulation model was validated throughout the life cycle of the study to ensure that it adequately represented the behaviour of the real life service. Specific validation activities included presenting the model in detail to a group of key stakeholders where modellers and stakeholders had the opportunity to ask questions and suggest alterations. Following minor changes stakeholders found the simulation model and its results to be representative of their experience of the system. Furthermore, the results of the baseline model, which represented the care service as was resourced at the time of the study, were compared with past obesity service data. The simulation results, such as the number of patients discharged from the lifestyle, pharmacotherapy and surgical treatments and the average waiting time to surgery, compared favourably with the actual service statistics as at the end of December 2009. For example, the total number of patients discharged from the service over a year was $152,95 \%$ CI (100 to 171 ) vs 152 actual patients discharged, the total number of surgeries completed was 92, 95\% CI (60 to 123) vs 85 actual surgeries carried out, the average waiting time to surgery was 11 weeks, 95\% CI (10 to 13$)$ vs 10 weeks achieved by the end of 2009). The service data provided were based on the past year (2009) at the time of the validation so it was important to also consider the percentage increase in referrals as the baseline simulation model simulates a year into the future. This figure is considered acceptable given that approximately higher patient referrals were used in the model to account for the increased demand for services in the 1 year into the future (1187 instead of 952 actual referrals by the end of 2009). The model behaved as expected. We could not compare the model retrospectively with data of the year simulated as capacity changes were introduced to the actual system as a result of the study partway through the year (2010). Sensitivity analysis was also undertaken in order to check the impact of referral rate changes on model results. A $\pm 5 \%$ change in this parameter incurred a proportional change in the results. A similar model behaviour was obtained by changing the time period between appointments. The stakeholders were made aware of these findings.

\section{RESULTS}

The results of the baseline scenario (table 3 ) showed that a high backlog of patients would accumulate in the different waiting lists, if the same level of resources were kept in a simulated year (at the time of the study a year into the future). The rising figures are not due to any transient effects or an insufficient warm-up period but are due to the rising referrals. This result was in line with the expectations of the obesity care service team members. On an annual basis, an average 64\% (95\% CI 63\% to 65\%) of patients waited for more than 18 weeks until being seen at the eligibility visit or pharmacotherapy clinic from first referral and 47\% (95\% CI 46\% to 47\%) of surgical pathway patients would wait for more than 18 weeks for an operation from the Eligibility visit. These figures continued to rise, reaching to $100 \%$ in the last month (December of a simulated year).

Comparing the simulation results of all six scenarios, scenarios 3 and 5 were the best performing ones in terms of patient waiting times in the service. The 


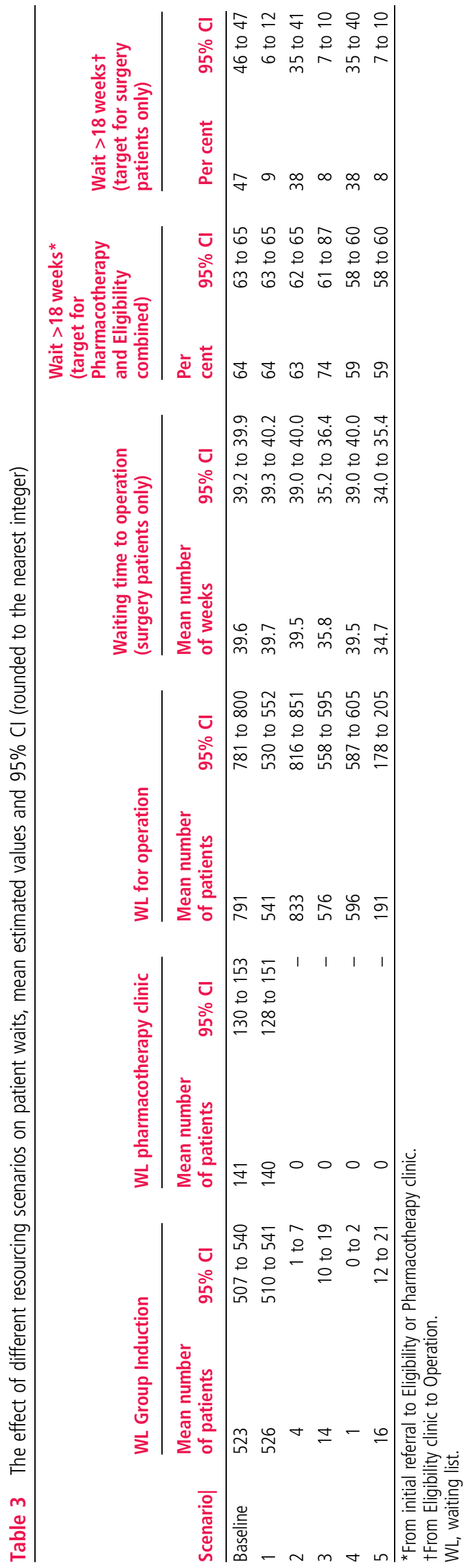

proportion of patients waiting for longer than 18 weeks was reduced to $9 \%(95 \%$ CI $9 \%$ to $12 \%)$ with the addition of one surgeon (scenario 1), whereas the addition of two surgeons (scenarios 3 and 5) provided a further slight improvement, reducing this proportion to $8 \%$ (95\% CI $7 \%$ to $10 \%)$.

The introduction of an additional physician resulted in significantly lower waiting lists for group induction, Pharmacotherapy and Eligibility clinic (scenario 2). However, more patients progressed to the surgical part of the system, creating a high backlog of referrals waiting for surgery. This is obvious when comparing scenarios 1 ( 1 physician) and 2 ( 2 physicians), where a higher proportion of patients waited for more than 18 weeks (9\% compared with 38\%). The best performing scenarios were those with more surgeons than physicians. This demonstrates the dynamic behaviour of resources and the bottlenecks created in the system.

Scenarios 4 and 5 operate under a reduced patient referrals mechanism, where patients who did not have sleep apnoea, high cardiovascular risk, diabetes or infertility would be seen by general practitioners in primary care centres. The reduced referral rate appears to allow physicians to clear the backlog of patients waiting for group induction. As a result the proportion of patients waiting for more than 18 weeks to be seen at the Eligibility clinic is reduced from 63\% (95\% CI $62 \%$ to $65 \%$ ) in scenario 2 to $59 \%$ (95\% CI $58 \%$ to $60 \%)$ in scenarios 4 and 5 . In the last month (December year 1) this proportion reaches 0\% (scenarios 4 and 5). Scenario 5 however provided a better performance because beyond December of year 1, all patients wait less than 18 weeks to be seen at the Eligibility clinic or to receive an operation.

\section{DISCUSSION}

Members of the obesity care team were involved throughout the study and took a keen interest in its results. The simulation models built provided a visual representation of the obesity care service, which in turn helped those involved in gaining a wider understanding of the service. The study confirmed the initial concerns of the team that the pre-existing capacity in place in 2009 (at the start of study), would not be sufficient to cope with the increases in patient referrals to the service. In real life this would result into continuously rising numbers of patients on the waiting lists with considerably longer waits. Hence changes needed to be considered. As expected, simulation results showed that the addition of surgical resources and their associate capacity bring about improvements in patient waiting times in the surgical part of the service. However, the results also showed that adding at the same time the capacity of one physician, may lead to deterioration in the waiting times associated with the surgical part of the service. This occurs because a 'bottleneck' is developed between 
the physician-led clinics and the surgical part of the service, with the latter not having the available capacity to accommodate the number of additional patients placed on the surgical waiting lists. Better service levels were achieved when the modelled service operated with the concurrent capacity of two physicians and three surgeons. This finding served as evidence for the obesity team and its management that staffing decisions in relation to one part of the service should not be taken in isolation to other parts of the service.

Furthermore, the results showed that reasonable and realistic expansions in capacity alone cannot improve service performance levels. Introducing the concept of 'demand management' for treatment whereby controlling the number of patients referred to the service and focusing on those that would benefit would result in a reduction of referral rates to the obesity care service. Study results confirmed that a reduction by almost $50 \%$ in referral rates would ensure that the service be in a better position to meet demand. This finding calls for a more integrated approach to planning for obesity care services, involving care providers at primary, secondary and tertiary levels, as suggested also by Gortmaker et al. ${ }^{5}$

As an immediate outcome of this study the Trust decided to add more surgeons to the service instead of adding physicians alone. Furthermore, the Academic Health Science Centre and the Primary Care Trust engaged into discussions about changing the local eligibility criteria for bariatric surgery, ${ }^{23}$ which eventually led to a reduction in the number of referrals to the centre. A decision to build a new operating theatre was also made as the management team realised that additional capacity was needed in order to achieve aspired service levels and operation volumes.

\section{CONCLUSIONS}

The simulation study reported here is to the best of our knowledge, the first computer simulation study of an obesity service reported in the literature. The simulation model demonstrated the dynamic nature and impact between different parts of the service, highlighting the need to introduce changes in capacity after careful consideration of their impact on the overall performance of the service. Unlike many healthcare simulation models built of an individual microsystem, ${ }^{11-16}$ this model represents a complex clinical service comprising of many microsystems serving the same patient population. This is a novel conceptual view.

The model reported here represents what was considered to be a complex multidisciplinary obesity care service, to an acceptable level of accuracy. In the specific obesity care services, complexity exists because at different stages of the pathway a wide range of investigations and treatment options are available to the patients. Furthermore, the clinical treatment of obesity often requires intentional delays in treatment, while the patient undergoes preparation or an initial weight loss programme. ${ }^{7}$ Such delays are clinically beneficial for the patient as it may improve the outcome of their treatment, ${ }^{7}$ but it adds to the complexity that needs to be accounted for in planning and consequently in the model. In addition the variability found in the real system (eg, referral rates and delays) is captured through the use of empirical and statistical distributions. To a certain extent, only through a simulation model can this level of complexity due to interconnectedness and variability be captured adequately. ${ }^{24-26}$

The main objective of the study was to understand the performance of targets relating to system throughput times such as the 18 week target. ${ }^{9} 2426$ The model does not include a detailed representation of the microsystems. For example resources in each microsystem were translated into capacity and more specifically patient slots. However one can infer from this capacity and associated resources the corresponding costs as well as the need for new investment. In this study hospital planners were able to translate patient slots to the resources required and the associated costs. The cost-benefit trade-offs of new investments in high cost staff such as consultant physicians and surgeons remain an important determinant of any decision within a health system. This simplification was necessary to enable us to focus on the key aim of the study and to keep the complexity of the model to a minimum. Future simulation studies, for example, could consider extending the existing model to include follow-up (repeat) appointments.

Computer simulation provides a visual representation of the system in a model that enables modellers and stakeholders to interact with it while it is running. The models showed patients flowing through the different clinics, with queues building and statistical results displayed on demand. This can be useful to many healthcare providers who are often not aware of the impact of a decision on other parts of the system. Running these models with stakeholders present helped communication between the healthcare stakeholders and the modelling team. During the experimentation stage the stakeholders were able to visually experience the model running and suggest scenarios to be explored, for example adding capacity in different parts of the model. Many of these scenarios were run at the stakeholders' request. In addition, during this experimentation with scenarios, stakeholders could request changes to the model's capacity that in real life may be considered unaffordable. The outcome of such changes was known in a few minutes. This level of experimentation could not have been undertaken in real life as most systems cannot afford to add expensive structures without being sure it will alleviate the problem. Therefore, computer simulation modelling, as this study has shown, can support experimentation 
in a safe environment and the results can be made quickly available to those concerned.

Contributors AAT built the models and analysed the results. AAT and KK drafted the paper. CV helped with the editing of the paper. AM and CWR helped in organising the study, contributed data for the development of the models and editing of the paper. All authors have reviewed the paper and have approved the final version.

Funding This study was supported by the UK Engineering and Physical Sciences Research Council (EPSRC) grant EP/E045871/1.

\section{Competing interests None.}

Provenance and peer review Not commissioned; externally peer reviewed.

Open Access This is an Open Access article distributed in accordance with the terms of the Creative Commons Attribution (CC BY 3.0) license, which permits others to distribute, remix, adapt and build upon this work, for commercial use, provided the original work is properly cited. See: http://creativecommons.org/licenses/by/3.0/

\section{REFERENCES}

1 World Health Organization. Obesity and Overweight. 2011. http://www.who.int/mediacentre/factsheets/fs311/en/ (accessed 25 Feb 2013).

2 Butland BS, Jebb P, Kopelman, et al. Foresight. Tackling obesities: future choices. Government Office for Science, 2007.

3 Flegal KM, Carroll MD, Ogden CL, et al. Prevalence and trends in obesity among US adults, 1999-2008. JAMA 2010;303:235-41.

4 Swinburn BA, Sacks G, Hall KD, et al. The global obesity pandemic: shaped by global drivers and local environments. Lancet 2011;378:804-14.

5 Gortmaker SL, Swinburn BA, Levy D, et al. Changing the future of obesity: science, policy, and action. Lancet 2011;378:838-47.

6 Royal College of Physicians. Action on obesity: comprehensive care for all, report of a working party. 2013. http://www. rcplondon.ac.uk/sites/default/files/action-on-obesity.pdf (accessed 28 Jul 2013].

7 NHS Choices. Guide to waiting times. NHS Choices website. 2011. http://www.nhs.uk/choiceintheNHS/Rightsandpledges/ Waitingtimes/Pages/Guide\%20to\%20waiting\%20times.aspx (accessed 25 Feb 2013).

8 Department of Health. The Operating Framework for the NHS in England 2011/12. 2010. http://www.dh.gov.uk/prod_ consum_dh/groups/dh_digitalassets/@dh/@en/@ps/documents/ digitalasset/dh_122736.pdf (accessed 25 Feb 2013).

9 Jun JB, Jacobson SH, Swisher JR. Application of discrete-event simulation in health care clinics: A survey. J Operational Res Soc 1999;50:109-23.

10 Bowers J. Waiting list behaviour and the consequences for NHS targets. J Operational Res Soc 2009;61:246-54.
11 Rohleder TR, Lewkonia P, Bischak DP, et al. Using simulation modeling to improve patient flow at an outpatient orthopeadic clinic. Health Care Manag Sci 2010;14:135-45.

12 Clague JE, Reed PG, Barlow J, et al. Improving outpatient clinic efficiency using computer simulation. Int J Health Care Qual 1997;10:197-201.

13 Everett J. A decision support simulation model for the management of an elective surgery waiting system. Health Care Manag Sci 2002;5:89-95.

14 Ramwadhdoebe $S$. A tutorial on discrete-event simulation for health policy design and decision making: Optimizing pediatric ultrasound screening for hip dysplasia as an illustration. Health Policy 2009;93:143-50.

15 Reynolds M, Vasilakis C, McLeod M, et al. 2011. Using discrete event simulation to design a more efficient hospital pharmacy for outpatients. Health Care Manag Sci 14: 223-36.

16 Weerawat W, Pichitlamken J, Subsombat P. A generic discrete-event simulation model for outpatient clinics in a large public hospital. J Healthc Eng 2013;4:285-305.

17 National Institute for Health and Clinical Excellence. Obesity: guidance on the prevention, identification, assessment and management of overweight and obesity in adults and children (NICE clinical guideline 43). 2006. http://www.nice.org.uk/ nicemedia/live/11000/30365/30365.pdf (accessed 25 Feb 2013).

18 Welbourn R, Fiennes A. National Bariatric Surgery Registry. UK: Dendrite Clinical Systems ltd, 2011.

19 Simul8 Corporation. http://www.simul8.com/ (accessed 25 Feb 2013).

20 Law AM. Simulation modeling and analysis. Boston, London: McGraw-Hill, 2007.

21 Robinson S. Simulation: the practice of model development and use. Chichester: John Wiley \& Sons, 2004.

22 Hoad K, Robinson S, Davies R. Automated selection of the number of replications for a discrete-event simulation.

J Operational Res Soc 2010;61:1632-44.

23 Bariatric Surgery. NHS North West London. 2012. http://www. northwestlondon.nhs.uk (accessed 5 Mar 2013).

24 Pitt M. Simulation for Strategic Planning in Healthcare: the State of the Art. Briefing report for the NHS Institute. 2008. http://www.institute.nhs.uk/images//documents/ BuildingCapability/ScenarioGenerator/state-of-the-art.pdf (accessed 3 Mar 2013).

25 Fone D, Hollinghurst S, Temple M, et al. Systematic review of the use and value of computer simulation modelling in population health and health care delivery. J Public Health Med 2003;25:325-35.

26 Sobolev B, Sanchez V, Vasilakis C. Systematic review of the use of computer simulation modeling of patient flow in surgical care. J Med Syst 2011;35:1-16. 